\title{
Probable Relationship between COVID-19, Pollutants and Meteorology: A Case Study at Santiago, Chile
}

Special Issue:

Special Issue on COVID-19 Aerosol Drivers, Impacts and Mitigation (XIII)

\section{OPEN ACCESS}

Received: July 23, 2020

Revised: December 9, 2020

Accepted: January 14, 2021

\author{
* Corresponding Authors: \\ Giovanni A. Salini \\ gsalini@ucsc.cl \\ Patricio R. Pacheco \\ patricio.pacheco@utem.cl
}

\section{Publisher:}

Taiwan Association for Aerosol Research

ISSN: $1680-8584$ print

ISSN: 2071-1409 online

(c) Copyright: The Author(s).

This is an open access article distributed under the terms of the Creative Commons Attribution License (CC BY 4.0), which permits unrestricted use, distribution, and reproduction in any medium, provided the original author and source are cited.

\author{
Giovanni A. Salini ${ }^{1 *}$, Patricio R. Pacheco ${ }^{2 *}$, Eduardo Mera², María C. Parodi ${ }^{3}$ \\ ${ }^{1}$ Departamento de Matemática y Física Aplicadas, Facultad de Ingeniería, Universidad Católica \\ de la Santísima Concepción, Alonso de Ribera 2850, Concepción, Chile \\ ${ }^{2}$ Departamento de Física, Universidad Tecnológica Metropolitana, Las Palmeras 3360, Ñuñoa \\ Santiago, Chile \\ ${ }^{3}$ Departamento de Industria, Facultad de Ingeniería, Universidad Tecnológica Metropolitana, \\ José Pedro Alessandri 1242, Ñuñoa, Santiago, Chile
}

\section{ABSTRACT}

We present here a study about the possible spread of covid-19 pandemic between human's beings through aerosols contained in urban air polluted by respirable particulate matter and tropospheric ozone, as well as the incidence of local meteorology in an area with orographic basin characteristics and in a certain period of time. Hourly time-series data of three meteorological variables - temperature, relative humidity, wind speed-and three pollutants-PM $10, \mathrm{PM}_{2.5}$ and $\mathrm{O}_{3}$-were considered together with hourly data from the highest number accumulated sick's in seven communes - chosen at random-in Santiago, Chile, studying a probable link between them. From the epidemic perspective, the infected patients number was linked to the hourly time-series of meteorological and pollutant variables, generating new time-series. Nonlinear analysis and the chaos theory formalism was applied to these new time-series, obtaining the largest Lyapunov exponent, correlation dimension, Kolmogorov entropy, Hurst exponent and the Lempel-Ziv complexity. Our preliminary results show meteorological and air pollution variables can be part of the elements fraction that give sustainability to the accumulated growth of infected patients and favor the pandemic spread, making the accumulated sick's curve chaotic and complex. In addition, environmental pollution could worsen disease conditions like coronavirus (COVID-19) infection. For all time-series, the Lempel-Ziv complexity turned out to be between 0 and 1 which is indicative of connectivity and chaos. The largest Lyapunov exponent as well as the Kolmogorov entropy were positive which also exhibits chaos. The Hurst exponent was found to be greater than 0.5 and less than 1 for all time-series, indicating positive long-term autocorrelation. Finally, the correlation dimension was less than 5, revealing that new time-series constructed are not random.

Keywords: Coronavirus, Air pollution, Entropy, Chaos, SARS-CoV-2

\section{INTRODUCTION}

\subsection{Coronavirus-types}

The current pandemic that is ravaging the planet (COVID-19) is a variant of coronavirus with a RNA envelope that causes respiratory diseases of varying severity, from the common cold to fatal pneumonia. Various coronaviruses, such as the one discovered in the 1930s in poultry, caused respiratory, gastrointestinal, liver and neurological diseases in animals. Only 7 disease-causing coronaviruses are known in human beings. Most time, 4 of the 7 coronaviruses cause symptoms of the common cold. Types 229E and OC43 are responsible for the common cold; Serotypes NL63 and HUK1 were discovered, which were also associated with the common cold. Rarely, serious respiratory tract infections, including pneumonia, can occur, especially in infants, the elderly, 
and immunocompromised persons. Three of the 7 coronaviruses cause respiratory infections in humans much more severe and even more fatal than the other coronaviruses and are the cause of pneumonia major outbreaks, fatal to humans, in the $21^{\text {st }}$ century (Wilks et al., 2003).

SARS-CoV was identified in 2002 as the cause of major severe acute respiratory syndrome outbreaks (SARS). MERS-CoV was identified in 2012 as the cause of Middle East respiratory syndrome (MERS). SARS-CoV-2 is a new coronavirus identified as the cause of 2019 coronavirus disease (COVID-19) that started in Wuhan, China in late 2019 and has spread throughout the world. These coronaviruses, which cause severe respiratory infections, are zoonotic pathogens, which start in infected animals and spread from animals to people. COVID-19 is an acute, sometimes severe, respiratory disease caused by a novel SARS-CoV-2 coronavirus (CDC, 2020b). The transmission mechanism is still being investigated, and to date it is observed that it is equivalent to influenza (Xu et al., 2020), although it seems more transmissible than SARS.

Situations with a high risk of transmission include institutions such as nursing homes, longterm care centers, prisons, boats and, in general, where many people are concentrated. These situations involve high population density and often lead to difficulties in maintaining safety precautions. Through quarantine and isolation measures, attempts are made to limit the local, regional and global spread of this outbreak. Strict compliance with these measures has given satisfactory results in controlling the infection spread, in selected areas, in countries that have followed the suggestions and warnings given by the WHO (maintain social distance, wear face masks or masks and handwashing). SARS is much more severe than other coronavirus infections, and includes surfaces. Tests on stainless steel and plastic showed that a percentage of the virus survived and retained its infectious capacity for up to three days. These findings suggest that the virus could remain this amount of time on laminated or laminated door handles, countertops (or seats) and other hard surfaces (Kampf et al., 2020). SARS is a flu-like illness that sometimes culminates in severe progressive respiratory failure (CDC, 2020a, b; JHMI, 2020).

\section{2 $\mathrm{PM}_{2.5}$ and $\mathrm{PM}_{10}$ Particulate Matter}

Particulate matter is found in dust, ash, soot, metal particles, cement, or pollen. Other sources are coal industrial and domestic combustion from industrial processes fires, wind erosion and volcanic eruptions, buildings, demolitions and so on (Zereini and Wiseman, 2010; Fuzzi et al., 2015; Đorđević et al., 2020). The main effects on human health range from irritation to the respiratory tract, deposition in the lungs causing diseases such as silicosis and asbestosis, as well as worsening asthma and cardiovascular disease (Fishman and Crutzen, 1978; Schwartz et al., 2002; Cakman et al., 2007; Brook et al., 2010; Cassee et al., 2011; Lee et al, 2014). All kinds of surfaces (houses, public sculptures, etc.) also experience deterioration. They affect vegetation by interfering with photosynthesis. In the environment, they decrease visibility and induce cloud formation (Iwasaka et al., 1983). Its effects are also manifested in height (Salini and Medina, 2017), as well as in medium-sized cities (Salini, 2018).

The World Health Organization (WHO, 2013) recommends as a limit for coarse particulate matter $\left(\mathrm{PM}_{10}\right) 20 \mu \mathrm{g} \mathrm{m}^{-3}$, for annual average; and $50 \mu \mathrm{g} \mathrm{m}^{-3}$ for average in $24 \mathrm{~h}$. For fine particulate matter $\left(\mathrm{PM}_{2.5}\right), 10 \mu \mathrm{g} \mathrm{m} \mathrm{m}^{-3}$ of annual average, and $25 \mu \mathrm{g} \mathrm{m}^{-3}$ for average in $24 \mathrm{~h}$.

\subsection{Tropospheric Ozone $\left(\mathrm{O}_{3}\right)$}

This is a powerful oxidant that produces adverse effects on human health (Walker, 1978; Grewe, 2006; Saliba and Massoud, 2011). Short-term studies show that $\mathrm{O}_{3}$ concentrations (especially in the summer) have adverse effects on respiratory function, causing lung inflammation, respiratory failure, asthma, and other bronchopulmonary diseases. Several European investigations have shown that daily mortality rises with increasing exposure to ozone. There is also new evidence linking long-term exposure to ozone with greater effects than previously thought in terms of impaired reproductive health and mortality. Since 2005, several cohort analyzes have been published on long-term ozone exposure and respiratory mortality. Furthermore, there is evidence in cohort and mortality studies among people with previous diseases (chronic obstructive pulmonary disease (COPD) or chronic obstructive pulmonary disease (COPD), diabetes, heart failure, heart attack, etc.). In addition to its impacts on human health, vegetation and crops, ozone is currently considered the third most important greenhouse gas (after carbon dioxide and 
methane). According to the WHO $(2006,2013)$, the eight daily average hours of concentration for tropospheric ozone is $100 \mu \mathrm{g} \mathrm{m}^{-3}$ (51 ppb).

\section{METHODOLOGY}

\subsection{The Data}

The data from seven $\mathrm{PM}_{10} / \mathrm{PM}_{2.5}$ and tropospheric ozone $\left(\mathrm{O}_{3}\right)$ monitoring station in Santiago is analyzed in this study, where their locations are shown in Fig. 1 and they report 1-hour averages. Meteorological data like temperature (T), wind speed (VV), and relative humidity (HR) are also measured in these stations. The data were obtained from National Air Quality Information System (SINCA in Spanish, dependent on MMA). These data make up time series for 2.5 months (March 30-June 15). Accumulated sick's data were obtained from Chile's Health Ministry (MINSAL), which summarizes Table 1 and shows the communes present on study with their inhabitants (Census, 2017).

Three pollutants selection-especially $\mathrm{O}_{3}$-is based on the fact that they have an adverse effect on the human being's respiratory tract, generating a picture of pre-existing diseases before the pandemic advent. There is a connected urban meteorology that arises from urban heat islands and urban canyons, apart from the basin geography of the area. A large number of local climatic zones are present depending on the size and city complexity; thus, sectors can be recognized according to their predominant socio-ecological characteristics. These sectors make up socioclimates or socially constructed climates based on the socioeconomic levels of their inhabitants

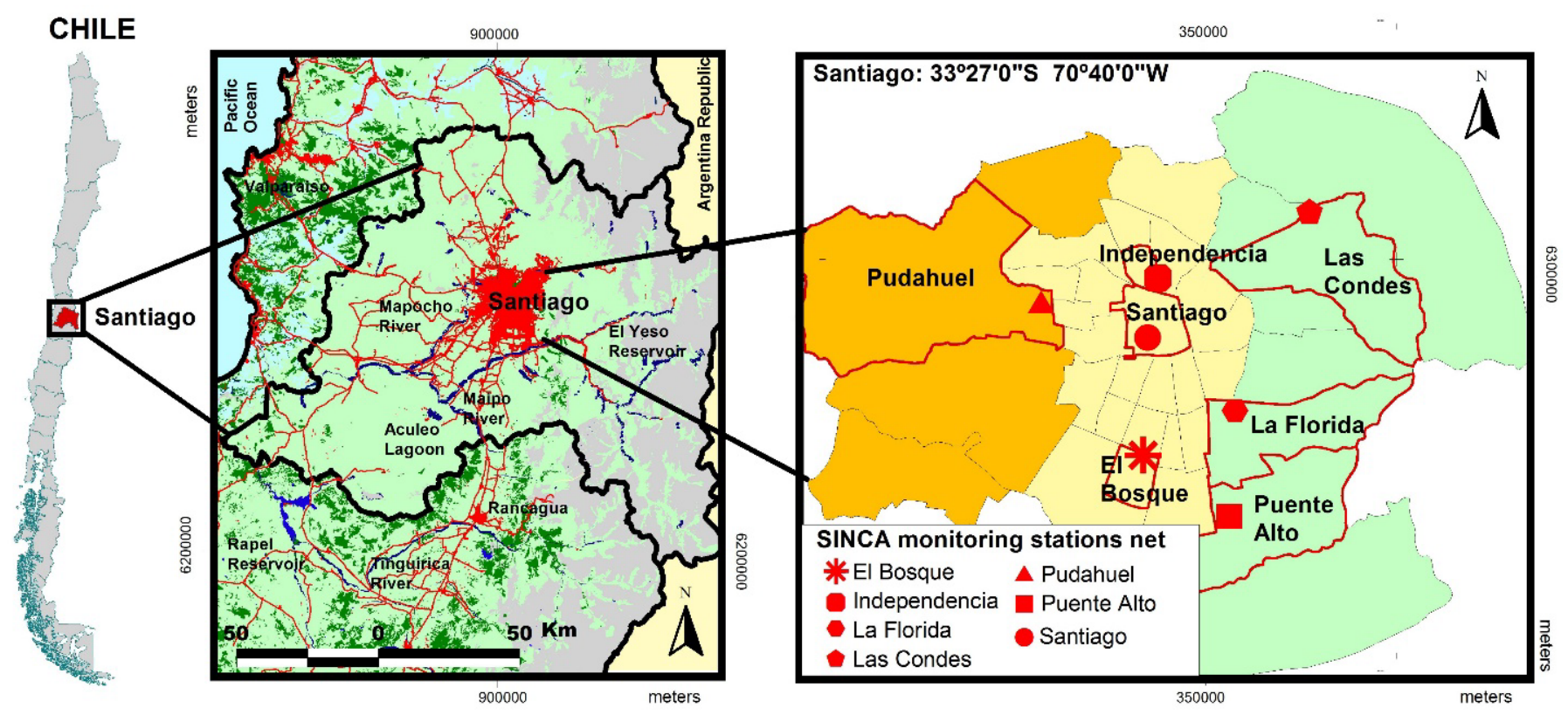

Fig. 1. Map of Metropolitan Area of Santiago, Chile.

Table 1. Study communes and inhabitants (Census, 2017).

\begin{tabular}{lll}
\hline Commune & Population (2017) & Accumulated sick's by study communes (2020) \\
\hline Santiago & 404495 & 9412 \\
Independencia & 100281 & 4300 \\
Las Condes & 294838 & 3623 \\
Puente Alto & 568106 & 12212 \\
El Bosque & 162505 & 3176 \\
La Florida & 366916 & 7633 \\
Pudahuel & 230293 & 4848 \\
Total & 2127434 & 451196 \\
\hline
\end{tabular}


and can be highly connected to indoor and /or outdoor, which favors the disease spread (Byass, 2020).

\subsection{Meteorological Variables}

In this study, nonlinear time series analysis tools were applied to local meteorological variables, such as temperature $(T)$, relative humidity $(\mathrm{RH})$ and wind speed magnitude (WS). These parameters vary both spatially and temporally, allowing the description of various atmospheric and thermodynamic processes associated with it (Iqbal, 2020).

In the case of the Metropolitan Region (MR) communes from Santiago city, there is also an orographic influence due to the area geographical basin nature, see Fig. 2. At the 2017 census, the Metropolitan Region had 7,037,000 inhabitants, the population of these seven selected communes represents approximately 30\% of the entire population (by 2020, Metropolitan Region inhabitant's projection is 7,987,723 inhabitants). Column 3 of Table 1 shows the population infected amount with COVID-19 for the period under study.

\subsection{Irreversible Processes}

From a historical point of view, thermodynamics has focused on the study of equilibrium processes in which determinism works correctly. Reversibility and order define these processes. However, Prigogine observes that far from the equilibrium situation, new types of structures appear spontaneously (Eckert et al., 1998). Out of the chaos, ordered structures arise that require a contribution of energy to conserve themselves, but do not maintain linear relationships, and cannot be predicted precisely due to their non-linear nature. Close to the point where dissipative

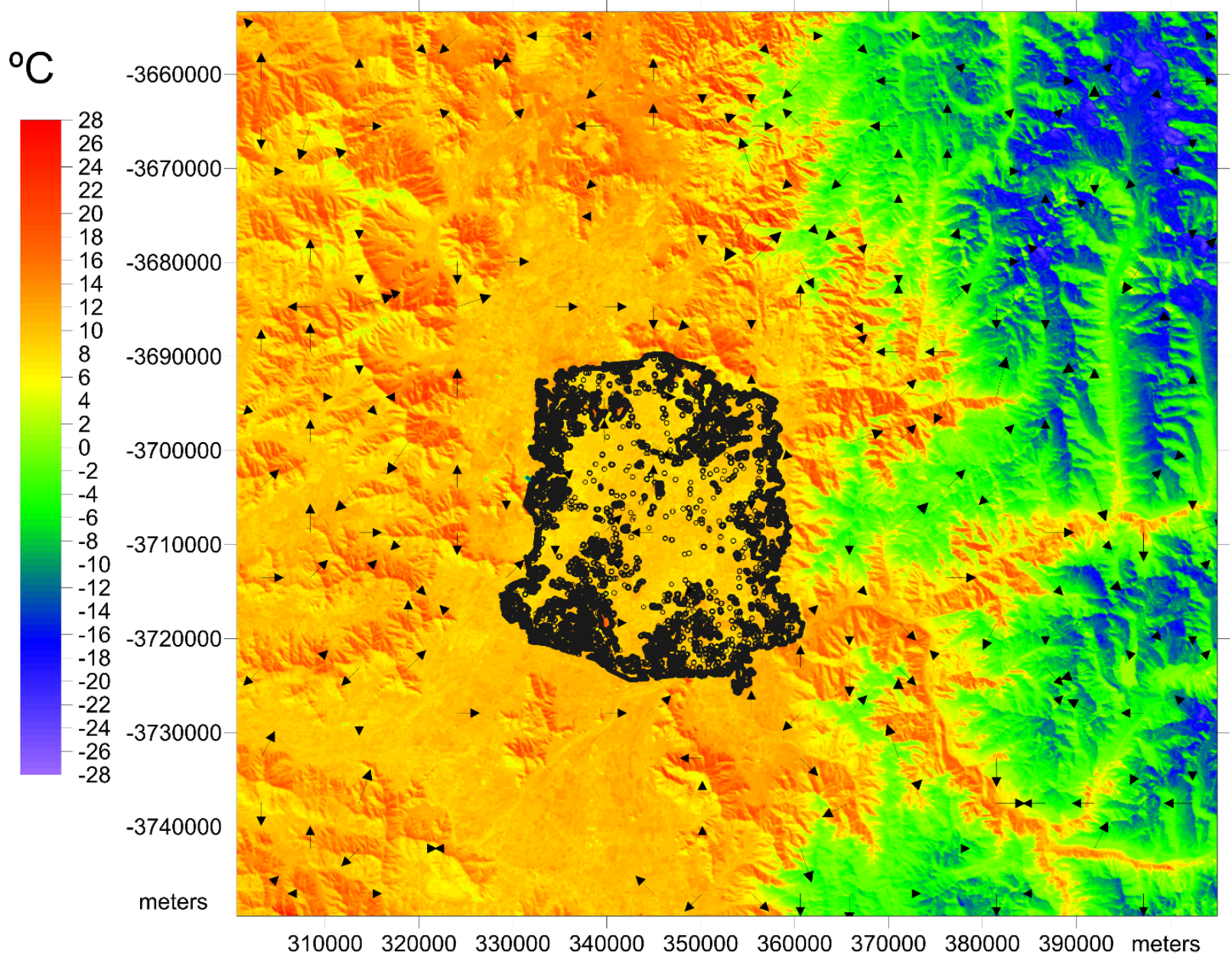

Fig. 2. Communal map of the Metropolitan Area and its thermal island (winter) with directions of temperature flow. Lansat 8 Image. 2015-2018 Images. Bands 4.5 and 10. (https://earthexplorer.usgs.gov/) 


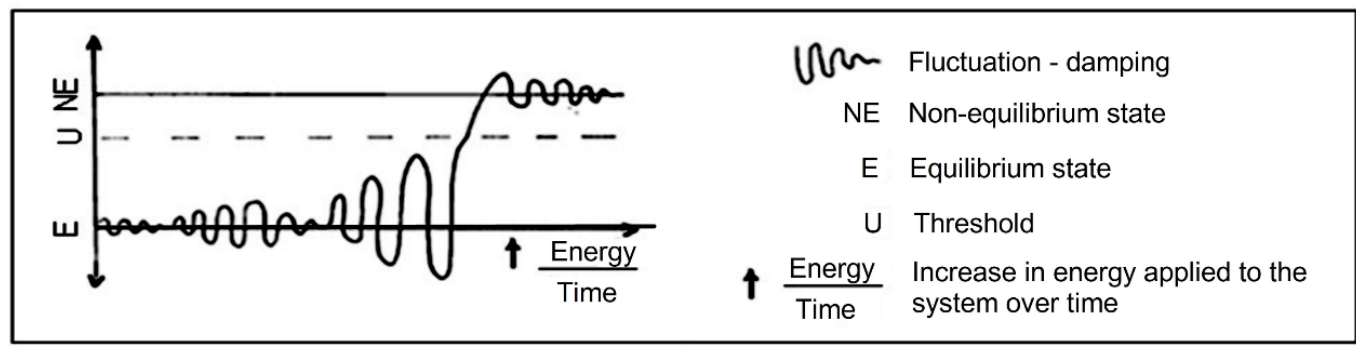

Fig. 3. Dynamics of dissipative structures (Manríquez, 1987).

structures are organized, large fluctuations are observed. Instead of being damped, they can spread throughout the system, leading to new situations that are qualitatively very different from those that are close to equilibrium. Thermodynamics shows how systems capable of moving away from determinism have to be placed far from equilibrium. We must distinguish between equilibrium conditions, non-equilibrium conditions, a process that leads from one to another and a threshold that separates them both. This situation is shown in Fig. 3, whose interpretation is the following: at the beginning, there are equilibrium conditions-whatever they are-in which fluctuations occur with respect to these conditions, attenuating with time. If energy is added to the system, the fluctuations begin to increase. However, the system still manages to dampen them. Until a certain instant is reached when a certain threshold, $U$, is exceeded. In this case, the fluctuations are no longer dampened, stabilizing in a state far from the equilibrium that it originally possessed but equally stable, while energy continues entering to the system. At this point, the system has formed a dissipative structure (Manríquez, 1987).

\subsection{Nonlinear Time Series Analysis and Chaos Theory}

Chaos theory is applied to the indicated data in order to analyze the possible relationships between them and their connection with general thermodynamic properties, such as entropy (Pacheco et al., 2019). The Lyapunov exponent $(\lambda)$ is defined as (Hilborn, 2000):

$\lambda=\frac{1}{n} \ln \frac{d_{N}}{d_{0}}$

where $\mathrm{N}$ is the iterations number. That is, if two points of an orbit are very close initially, this exponent for large $\mathrm{N}$ is calculated. If the points are separated after $\mathrm{N}$ iterations, there will be a possible chaos indication in that system. A positive value of the maximum Lyapunov exponent is chaos indication (Sprott, 2003). For a given time-series, the sum of all positive Lyapunov exponents defines its $S_{K}$ entropy and its reciprocal the mean predictability time, (Salini and Pérez, 2015; Chen et al., 2017):

$T_{P}=\frac{1}{S_{K}}$

In practice, the Lyapunov exponent is obtained from this equation at the large $\mathrm{N}$ limit, for which saturation is evident. For the same reason, and due to stability conditions in its calculation, ideally over 5,000 data should be kept and the largest Lyapunov exponents for all-time-series are calculated using the algorithm proposed by Wolf et al. (1985).

On the other hand, correlation entropy (Sprott, 2003) is defined as:

$K_{2}=\lim _{m \rightarrow \infty} \lim _{T \rightarrow \infty} \lim _{N \rightarrow \infty} \log \frac{C(m, r)}{C(m+1, r)} \sim S_{K}$

where $S_{k}$ is the Kolmogorov entropy; $C(m, r)$ is the correlation integral of the reconstructed trajectory of a time series; $m$ is the embedding dimension and $r$ is the circle radius whose center 
is on an object that is discrete points made up (in dimensions greater than two, the circles becomehyperspheres). $\mathrm{K}_{2}$ is zero, positive, or infinity for regular, chaotic, or random data, respectively. A method to estimate $K_{2}$ for experimental data is based on Grassberger and Procacia (1983). These relationships are part of the numerical calculation procedure applied to each time-series (both pollutants and meteorological variables), each of 1,872 data, since they do not present missing data.

The Hurst exponent is a measure of the degree to which the data can be represented by a random walk. Here, the root-mean-square displacement is calculated as a time function, where each point in the time-series is taken as an initial condition. The curve slope obtained is the Hurst exponent. For ordinary Brownian motion the exponent is 0.5 . Values between 0.5 and 1 indicate deterministic behavior and persistence. Hurst exponent significantly less than 0.5 is typical for deterministic behavior and anti-persistence (Kantz and Schreiber, 2005).

If the COVID-19 pandemic enters the human organism through the respiratory tract, then a connected urban meteorology that promotes sustainability and the pollutants diffusion makes its actions more effective, favoring the infection, cultivation and spread of diseases. To demonstrate this hypothesis, chaos theory is applied, considering the system as a dissipative structure. Virus effect is quantified from the patients accumulated over time together with meteorological variables and pollutants through the entropy that indicates diffusive capacity. Entropy also accounts for the natural evolution of the system towards states of higher probability.

\section{RESULTS AND DISCUSSION}

The time-series chaotic analysis was carried out using the Chaos Data Analyzer software (CDA, Sprott, 1995). The parameters that were studied were the Lyapunov exponent $(\lambda)$, Correlation Dimension (Dc), Correlation entropy (SK), Hurst (H) exponent. These indices confirmed the chaotic nature of the six-time-series belonging to each of the seven communes understudy. With these same time-series, the new hourly ratios were constructed: $X=A S / T ; Y=A S / W S ; Z=A S / R H ; W=$ $A S / P M_{10} ; U=A S / P M_{2.5}$ and $V=A S / O_{3}$. A new time-series family (42 in total) was originated, each one with 1,872 hourly data. AS is for the accumulated sick's per hour, and for each commune (data extracted from MINSAL). This process can be interpreted as a "transfer" of chaos-or entropy-from the meteorological and polluting variables to the accumulated sick's curve according to each commune. These new series are processed through the same software, with a total of 78624 data, all of which are chaotic, confirming the hypothesis of this research that meteorology and pollutants can dissipate a pandemic, increasing its complexity. The Iterated Function Systems (IFS) fragmentation test also suggests an analysis method of the data under study. The symbolic dynamics use (Horna et al, 2016) allows calculating the Lempel-Ziv (LZ) complexity relative to white noise. When the data is chaotic they are distributed forming, on a surface, localized groups. It is true for the 42 series since $0<L Z<1$, for chaotic data, which is shown in Table 2.

According to the data on period studied-and showed at Table 2-, the Hurts exponent for each time-series is persistent $(0.5<\mathrm{H}<1.0)$. c This is interpreted as "the following results strongly depend on the previous ones within a certain time period" having less entropy or predisposition to disorder and staying in time. For each commune, there is a decline in entropy as persistence increases, which favors the virus spread within each social urban "island". As the time-series under study-according to communes-, arise from the quotient between hourly accumulated sick's, with meteorological variables and hourly pollutants, it is shown that this relationship strengthens them and gives them strength supporting the study hypothesis: the meteorological variables and pollutants can form part of the elements fraction giving sustainability to the accumulated growth of the patients infected and the pandemic spread. This it shown in Fig. 4. The entropy growth is accompanied, with an asymptotic tendency, by growth of persistence loss, represented in Fig. 5 (both figures referred to Table 2).

From Table 3, (columns 5 and 6) and Table 4 (columns 6 and 7) it is observed that the environmental entropies (meteorological variables) are less than the anthropic ones (tropospheric pollutants), generating a mechanism of high connectivity that cooperates in the spread and pandemic persistence (Figs. 4 and 5).

Fig. 6 reveals that the entropy contribution from meteorological variables could cooperate in disease spread, of the characteristics of COVID-19, promoting the increase in infected rate. 
Fig. 7 indicates that the pollutants entropy emitted into the atmosphere can act cooperatively with meteorological variables, further increasing the sustainability and spread of a virus, accentuating the trend of Fig. 6.

Table 2. Chaotic indicators (by commune) for the time series under study.

\begin{tabular}{|c|c|c|c|c|c|}
\hline Communes & $\lambda[$ bits $/ \mathrm{h}]$ & $\mathrm{D}_{\mathrm{c}}$ & $\mathrm{S}_{\mathrm{k}}[\mathrm{bits} / \mathrm{h}]$ & $\mathrm{H}$ & $\mathrm{LZ}$ \\
\hline \multicolumn{6}{|c|}{ Las Condes (LC) } \\
\hline$x$ & $0.675 \pm 0.061$ & $1.626 \pm 0.306$ & 0.294 & 0.8980994 & 0.01585 \\
\hline$Y$ & $0.317 \pm 0.055$ & $4.166 \pm 0.545$ & 0.330 & 0.8320369 & 0.51153 \\
\hline Z & $0.131 \pm 0.036$ & $3.480 \pm 0.616$ & 0.254 & 0.8699403 & 0.42337 \\
\hline W & $0.786 \pm 0.064$ & $1.669 \pm 0.545$ & 0.564 & 0.8443708 & 0.48764 \\
\hline$U$ & $0.378 \pm 0.063$ & $1.462 \pm 0.037$ & 0.272 & 0.7711021 & 0.67889 \\
\hline V & $0.396 \pm 0.074$ & $1.440 \pm 0.053$ & 0.640 & 0.7754118 & 0.73784 \\
\hline \multicolumn{6}{|c|}{ Santiago (SANT) } \\
\hline$x$ & $0.558 \pm 0.056$ & $1.768 \pm 0.185$ & 0.389 & 0.8923760 & 0.01585 \\
\hline$Y$ & $0.073 \pm 0.054$ & $2.960 \pm 0.558$ & 0.505 & 0.6921257 & 0.51612 \\
\hline Z & $0.241 \pm 0.048$ & $3.616 \pm 0.662$ & 0.240 & 0.8567320 & 0.38544 \\
\hline W & $0.691 \pm 0.058$ & $2.353 \pm 0.407$ & 0.518 & 0.8544294 & 0.46023 \\
\hline$U$ & $0.319 \pm 0.061$ & $2.046 \pm 0.419$ & 0.534 & 0.7858549 & 0.63312 \\
\hline V & $0.288 \pm 0.067$ & $1.353 \pm 0.545$ & 0.458 & 0.7661108 & 0.69328 \\
\hline \multicolumn{6}{|c|}{ Independencia (IND) } \\
\hline$x$ & $0.500 \pm 0.056$ & $1.630 \pm 0.206$ & 0.378 & 0.8917318 & 0.01902 \\
\hline$Y$ & $0.198 \pm 0.063$ & $3.772 \pm 1.026$ & 0.443 & 0.7387629 & 0.39725 \\
\hline Z & $0.272 \pm 0.046$ & $4.348 \pm 0.962$ & 0.155 & 0.8550301 & 0.28933 \\
\hline W & $0.770 \pm 0.060$ & $1.713 \pm 0.107$ & 0.543 & 0.8635525 & 0.35081 \\
\hline$U$ & $0.640 \pm 0.071$ & $1.451 \pm 0.664$ & 0.480 & 0.8446618 & 0.57034 \\
\hline $\mathrm{V}$ & $0.424 \pm 0.081$ & $1.260 \pm 0.711$ & 0.386 & 0.8192579 & 0.70688 \\
\hline \multicolumn{6}{|c|}{ La Florida (LF) } \\
\hline$x$ & $0.536 \pm 0.052$ & $1.740 \pm 0.188$ & 0.354 & 0.8969514 & 0.02536 \\
\hline$Y$ & $0.196 \pm 0.055$ & $3.485 \pm 0.423$ & 0.377 & 0.7752033 & 0.46990 \\
\hline Z & $0.198 \pm 0.046$ & $3.397 \pm 0.593$ & 0.244 & 0.8350216 & 0.39771 \\
\hline W & $0.840 \pm 0.059$ & $2.278 \pm 0.260$ & 0.316 & 0.8521985 & 0.48625 \\
\hline$U$ & $0.546 \pm 0.071$ & $3.291 \pm 0.051$ & 0.440 & 0.8307689 & 0.70660 \\
\hline $\mathrm{V}$ & $0.380 \pm 0.078$ & $2.081 \pm 0.070$ & 0.518 & 0.8031664 & 0.71715 \\
\hline \multicolumn{6}{|c|}{ Puente Alto (PA) } \\
\hline$x$ & $0.560 \pm 0.056$ & $1.786 \pm 0.186$ & 0.384 & 0.8908278 & 0.02536 \\
\hline$Y$ & $0.194 \pm 0.056$ & $3.379 \pm 0.880$ & 0.414 & 0.8017714 & 0.42913 \\
\hline Z & $0.174 \pm 0.042$ & $3.958 \pm 0.764$ & 0.251 & 0.8972083 & 0.31780 \\
\hline W & $0.666 \pm 0.061$ & $2.356 \pm 0.152$ & 0.477 & 0.8486598 & 0.48340 \\
\hline$U$ & $0.387 \pm 0.068$ & $2.078 \pm 0.520$ & 0.353 & 0.8243979 & 0.65894 \\
\hline V & $0.440 \pm 0.076$ & $1.496 \pm 0.204$ & 0.469 & 0.7889941 & 0.73108 \\
\hline \multicolumn{6}{|c|}{ El Bosque (EB) } \\
\hline$x$ & $0.639 \pm 0.057$ & $1.739 \pm 0.208$ & 0.315 & 0.8943638 & 0.01585 \\
\hline$Y$ & $0.157 \pm 0.053$ & $3.347 \pm 0.758$ & 0.413 & 0.6864654 & 0.42515 \\
\hline Z & $0.206 \pm 0.042$ & $3.697 \pm 0.677$ & 0.230 & 0.8456352 & 0.27907 \\
\hline W & $0.960 \pm 0.059$ & $1.719 \pm 0.212$ & 0.487 & 0.8590738 & 0.33455 \\
\hline$U$ & $0.810 \pm 0.070$ & $1.646 \pm 0.223$ & 0.414 & 0.8304427 & 0.50682 \\
\hline V & $0.358 \pm 0.089$ & $1.106 \pm 0.168$ & 0.385 & 0.7820740 & 0.64869 \\
\hline \multicolumn{6}{|l|}{ Pudahuel(P) } \\
\hline$x$ & $0.582 \pm 0.055$ & $1.719 \pm 0.264$ & 0.306 & 0.8980994 & 0.02853 \\
\hline$Y$ & $0.237 \pm 0.059$ & $3.181 \pm 0.595$ & 0.508 & 0.7464291 & 0.43271 \\
\hline Z & $0.240 \pm 0.047$ & $3.579 \pm 0.542$ & 0.254 & 0.8414325 & 0.34681 \\
\hline W & $0.919 \pm 0.062$ & $1.533 \pm 0.262$ & 0.403 & 0.8616340 & 0.32561 \\
\hline$U$ & $0.067 \pm 0.061$ & $1.722 \pm 0.307$ & 0.283 & 0.8412599 & 0.26013 \\
\hline V & $0.560 \pm 0.090$ & $2.541 \pm 0.250$ & 0.474 & 0.8060385 & 0.70741 \\
\hline
\end{tabular}




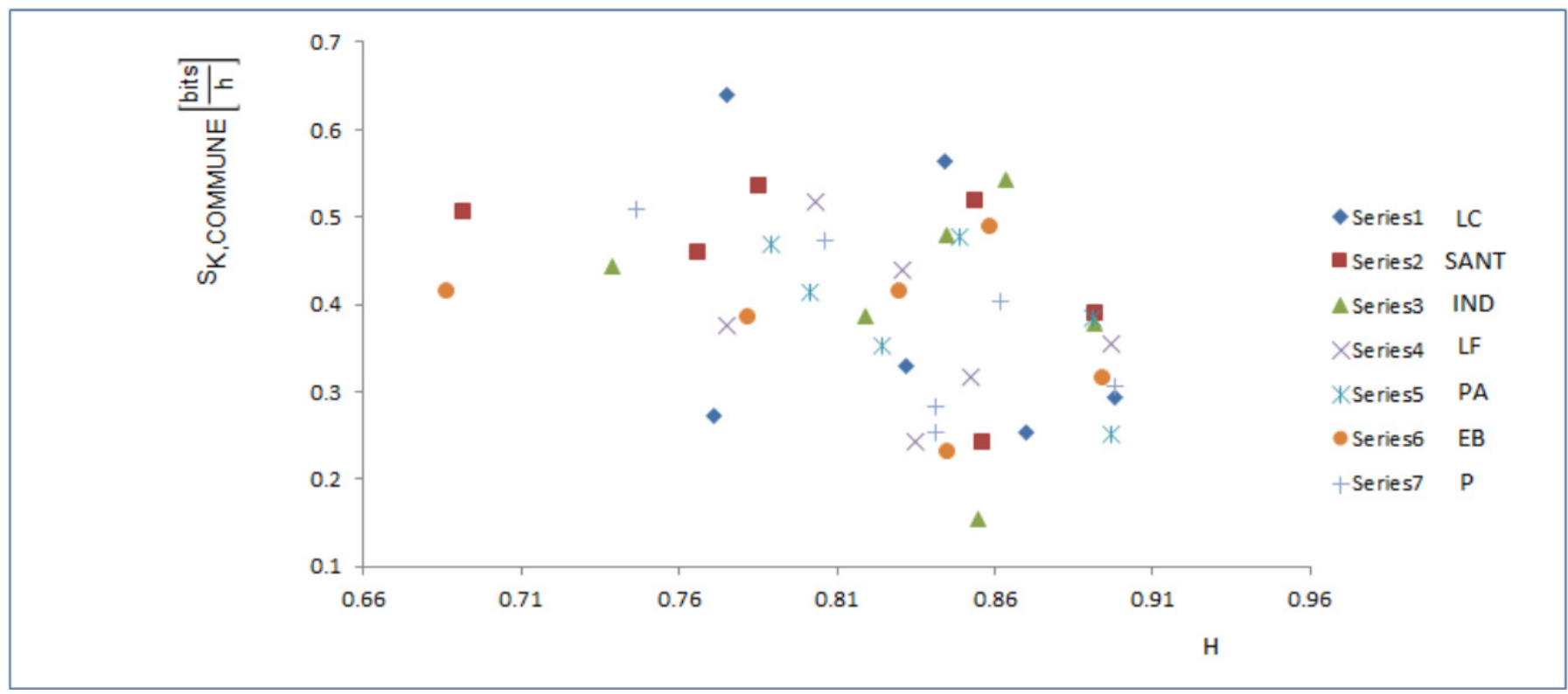

Fig. 4. Total entropies by commune versus persistence. The symbology of localities according to the series of data representation is indicated in Table 2.

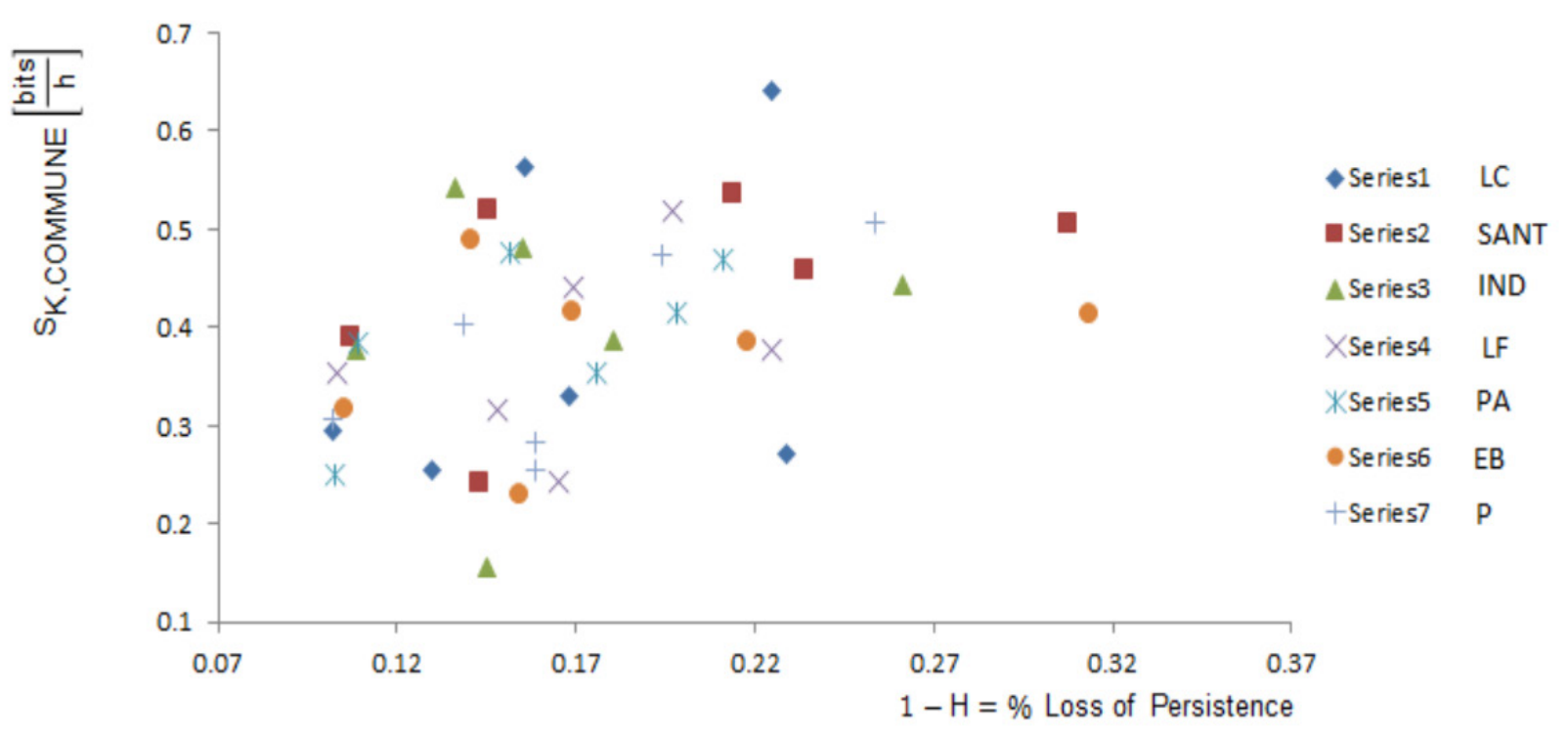

Fig. 5. Total entropies by commune versus Persistence loss percentage.

Table 3. Summary of the sum of entropies (Sk) X, Y and Z by commune ordered from highest to lowest according to entropy with accumulated sick's of the period under study.

\begin{tabular}{lll}
\hline Commune & Sxyz $[\mathrm{bits} / \mathrm{h}]$ & AS* \\
\hline Santiago & 1.134 & 9412 \\
Pudahuel & 1.068 & 4840 \\
Puente Alto & 1.049 & 12212 \\
Independencia & 0.976 & 4300 \\
La Florida & 0.975 & 7633 \\
El Bosque & 0.958 & 3176 \\
Las Condes & 0.878 & 3623 \\
\hline
\end{tabular}

* The third column is the number of sick accumulated by commune (From MINSAL (2020)). AS is for accumulated sick's. 
Table 4. Entropies of $S_{k w}$. $S_{k u}$ and $S_{k v}$ and their sum by commune. (The seventh column is the accumulated number of sick by commune for the study period).

\begin{tabular}{lllllll}
\hline & Commune & $\begin{array}{l}S_{K . W} \\
{[\mathrm{bits} / \mathrm{h}]}\end{array}$ & $\begin{array}{l}S_{K . U} \\
{[\mathrm{bits} / \mathrm{h}]}\end{array}$ & $\begin{array}{l}S_{K . V} \\
{[\mathrm{bits} / \mathrm{h}]}\end{array}$ & $\begin{array}{l}S_{K . W}+S_{K . U}+S_{K . V} \\
{[\mathrm{bits} / \mathrm{h}]}\end{array}$ & AS \\
\hline 1 & Santiago & 0.518 & 0.534 & 0.458 & 1.510 & 9412 \\
2 & Pudahuel & 0.403 & 0.283 & 0.474 & 1.160 & 4840 \\
3 & Puente Alto & 0.477 & 0.353 & 0.469 & 1.300 & 12212 \\
4 & Independencia & 0.543 & 0.480 & 0.386 & 1.409 & 4300 \\
5 & La Florida & 0.316 & 0.440 & 0.518 & 1.274 & 7633 \\
6 & El Bosque & 0.487 & 0.414 & 0.385 & 1.286 & 3176 \\
7 & Las Condes & 0.564 & 0.272 & 0.640 & 1.476 & 3623 \\
\hline
\end{tabular}

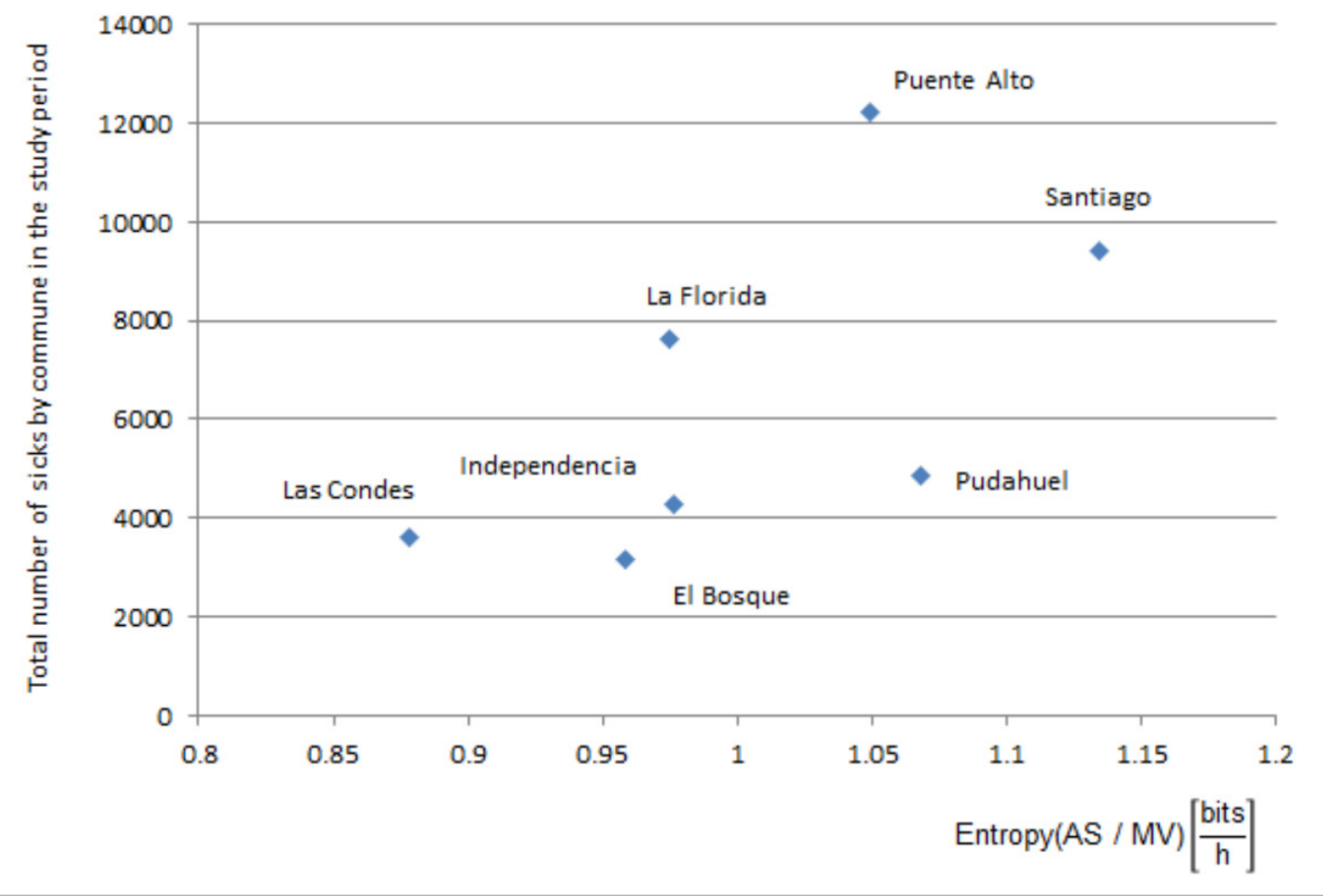

Fig. 6. Growth of sick accumulated by commune (in the study period) versus total entropy that adds the effect on sick accumulated by hour and by commune, of each hourly meteorological variable of the study.

A possible interpretation of Figs. 6 and 7 is as follows. Entropy can be considered as a random distribution measure for a system (consisting of time-series for each of the system representative variables: pollutants, meteorological variables and accumulated sick's). According to thermodynamics, the randomness degree or disorder in a system is called entropy. This is because a system in an unlikely condition will naturally tend to reorganize into a more likely condition. This reorganization will give rise to entropy increase, reaching a maximum when the system approaches equilibrium; thus, achieving a configuration with the highest probability or stability (Ruelle, 2003; Coccia, 2020). At the time of this study, the pandemic has not yet reached that state.

From an applied point of view and following the indicators provided up to mid-June 2020, Puente Alto, Peñalolén, La Florida, Santiago, Maipú, La Granja, San Bernardo are the municipalities with the highest number of active sick's and in decreasing order, La Pintana, Recoleta and Quilicura, corresponding to the low- and middle-income sectors. In Figs. 4 and 5 it can be seen that they are correctly incorporated in their trend. In many communes of the Santiago MR that is evaluated-based on the pieces number used exclusively as rooms and the inhabitants number of 


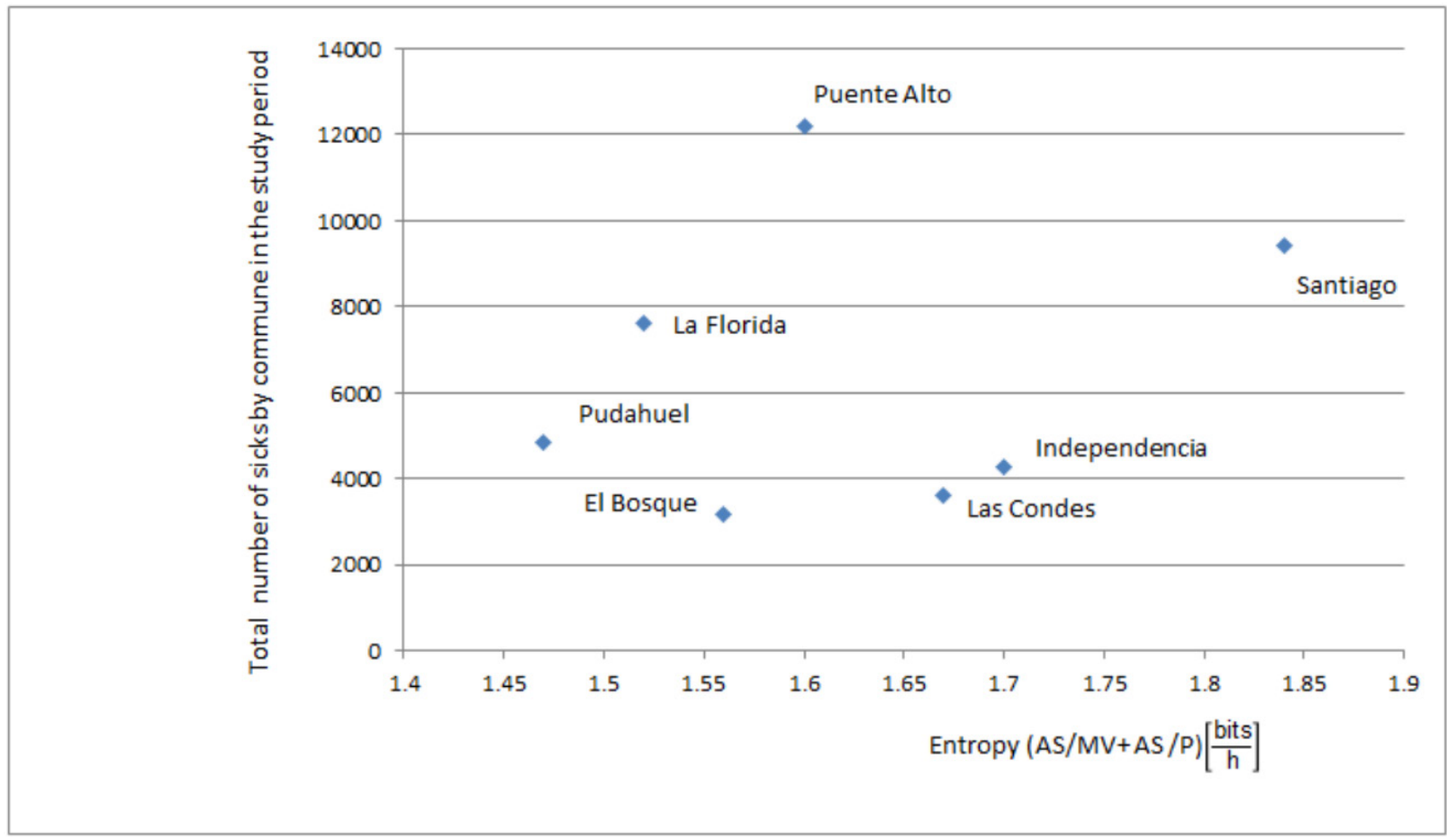

Fig. 7. Total entropy versus accumulated sick. A gradual increase in entropy and patients by commune is shown corresponding to Table 5.

Table 5. Total entropy that associates the accumulated sick by commune with the meteorological and pollutants variables.

\begin{tabular}{lll}
\hline Commune & $\mathrm{S}=\mathrm{S}_{x y z}+\mathrm{S}_{w}+\mathrm{S}_{u}+\mathrm{S}_{v}$ & Accumulated Sick's by study communes \\
\hline Santiago & 1.84 & 9412 \\
Independencia & 1.70 & 4300 \\
Las Condes & 1.67 & 3623 \\
Puente Alto & 1.60 & 12212 \\
El Bosque & 1.56 & 3176 \\
La Florida & 1.52 & 7633 \\
Pudahuel & 1.47 & 4848 \\
\hline
\end{tabular}

a dwelling, the greatest overcrowding affects the virus spread. When this ratio exceeds 2.4 people per room, it is considered overcrowding, according to the Mapcity study (Camhi, Betancourt, 2020). Thus, the overcrowding rate by commune: Independence: $13.1 \%$; Cerro Navia: $12.1 \%$; La Pintana: 12.0\%; San Ramón: 11.7\%; Recoleta: 11.6\%; Maipo Island: 11.6\%; Lo Espejo: 10.9\%; Central Station: 10.7\%; Renca: 10.3\%; Conchalí: 10.2\%. From the land uses point of view, design and construction materials used in streets and buildings, long-term studies (Rossi-Espagnet, 1983; Mouchet, 1997; Neiderud, 2015), show that they favor the formation of urban canyons, thermal islands, etc., elements recognized for not promoting the health of the population in cities (Acuto, 2020). It is shown that they rather favor the pandemic spread.

The parameters values calculated for all seven stations, including the largest Lyapunov exponent, is shown in Table 2, confirming that time-series under study are chaotic.

\section{CONCLUSIONS}

Weather and air pollution variables can be part of the elements fraction that give sustainability to the accumulated growth of infected patients, favoring the pandemic spread, making the accumulated sick's curve chaotic and increasing its complexity. Even more, environmental pollution could make diseases like the covid-19 coronavirus worse. 
For all time-series, the Lempel-Ziv complexity turned out to be between 0 and 1 which is indicative of connectivity and chaos. The largest Lyapunov exponent as well as the Kolmogorov entropy were positive which also exhibits chaos. The Hurst exponent was found to be greater than 0.5 and less than 1 for all time-series, indicating positive long-term autocorrelation. Finally, the correlation dimension was less than 5 , revealing that new time-series constructed are not random.

From our chaotic study applied to the six time-series representing the meteorology-pollutantaccumulated sick's interactive system, we were able to verify our hypothesis: a system made up of a connected urban meteorology that promotes sustainability and the pollutants spread, favors infection, cultivation and a coronavirus-type disease spread. This is due to system entropy, calculated for each studying commune, was greater than zero, revealing a trend towards a new equilibrium of the virus + meteorology + pollutants system, according to communes.

The population statistics overcrowding and active sick's, until mid-June 2020 and for our study communes, show agreement with this trend. Said scheme (Official Data COVID-19) indicates that the majority of these overcrowded communes are concentrated in the Chile central zoneincluding the communes considered in our study-with a greater number of active sick's.

We believe that our study will allow us to review the public health policies applied to the population. The chaotic analysis points to the weaknesses shown in the pandemic first stage in Chile. Learning stage for the authorities and the population, as in other parts of the world, which favored the accumulated sick's curve growth. Trend beginning to decrease in late June and early July, when the measures imposed by the authority-understood as necessary by the populationsuch as sanitation and public places cleaning, population confinement that caused a sharp decline in transport land-main responsible for air pollution in Santiago de Chile-, social distancing, health residences for infected, permanent hand hygiene, masks use, interregional health cords (with police and military control), permits granting through the internet for consumer goods purchases and regional travel. As a deterrent, very high fines were implemented for offenders. In addition, in Chile there was the natural seasonal transition from winter to spring (AugustSeptember) that manifests itself as a change in local meteorology (temperature, wind speed, relative humidity, among other climatic variables).

\section{ACKNOWLEDGMENTS}

The support from Dirección de Investigación and Facultad de Ingeniería, Universidad Católica de la Ssma. Concepción, is gratefully acknowledged. We also appreciate the support provided from Dirección de Investigación and Departamento de Física, Universidad Tecnológica Metropolitana.

\section{DISCLAIMER}

The authors declare no conflict of interests.

\section{REFERENCES}

Acuto, M. (2020). COVID-19: Lessons for an urban(izing) world. One Earth 2, 317-319. https://doi.org/10.1016/j.oneear.2020.04.004

Brook, R.D., Rajagopalan, S., Pope III, C.A., Brook, J.R., Bhatnagar, A., Diez-Roux, A-V., Holguin, F., Hong, Y., Luepker, R.V., Mittleman, M.A., Peters, A., Siscovick, D., Smith, S.C., Whitsel, L., Kaufman, J.D. (2010). Particulate matter air pollution and cardiovascular disease: An update to the scientific statement from the American Heart Association. Circulation 121, 2331-2378. https://doi.org/10.1161/CIR.0b013e3181dbece1

Byass, P. (2020). Eco-epidemiological assessment of the COVID-19 epidemic in China, JanuaryFebruary 2020. Global Health Action 13, 1760490. https://doi.org/10.1080/16549716.2020.1 760490

Cakman, S., Dales, R.E., Blanco, C. (2007). Air pollution and mortality in Chile: susceptibility among the elderly. Environ. Health Perspect.115, 524-527. https://doi.org/10.1289/ehp.9567

Camhi, R., Betancourt, N. (2020). Informe Mapcity: Comunas con mayor hacinamiento de la 
Región Metropolitana y la distancia que existe hasta su hospital más cercano. https://www.pauta.cl/ciudad/estudio-relaciona-hacinamiento-y-potencial-incidencia-de-covid-19

Cassee, F., Mills, N., Newby, D. (2011). Cardiovascular effects of inhaled ultrafine and nanosized particles, 1st edition, 2011. John Wiley \& Sons, Inc., Hoboken, NJ, USA.

Centers for Disease Control and Prevention (CDC) (2020a). Interim Guidelines for Collecting, Handling, and Testing Clinical Specimens from Persons for Coronavirus Disease. 2019. https://www.cdc.gov/coronavirus/2019-ncov/lab/guidelines-clinical-specimens.html

Centers for Disease Control and Prevention (CDC) (2020b). Severe Outcomes Among Patients with Coronavirus Disease 2019 (COVID-19) - United States, February 12-March 16, 2020. MMWR Morb. Mortal Wkly. Rep. 69, 343-346. https://doi.org/10.15585/mmwr.mm6912e2

Census (2017). XIX Censo Nacional de Población y VIII de Vivienda o Censo de Población y Vivienda 2017, Gobierno de Chile e Instituto Nacional de Estadísticas de Chile, https://www.ine.cl

Chen, Y., Wang, J., Feng, J. (2017). Understanding the fractal dimensions of urban forms through spatial entropy. Entropy 19, 600. https://doi.org/10.3390/e19110600

Coccia, M. (2020). Factors determining the diffusion of COVID-19 and suggested strategy to prevent future accelerated viral infectivity similar to COVID. Sci. Total Environ. 729, 138474. https://doi.org/10.1016/j.scitotenv.2020.138474

Đorđević, D., Milanković, J.D., Pantelić, A., Petrović, S., Gambaro, A. (2020). Coarse, fine and ultrafine particles of suburban-continental aerosols measured using an 11-stage Berner cascade impactor. Atmos. Pollut. Res. 11, 499-510. https://doi.org/10.1016/j.apr.2019.11.022

Eckert, K., Bestehorn, M., Thess, A. (1998). Square cells in surface-tension-driven Bénard convection: Experiment and theory. J. Fluid Mech. 356, 155-197. https://doi.org/10.1017/S00 22112097007842

Fishman, J., Crutzen, P.J. (1978). The origin of ozone in the troposphere. Nature 274, 855-858. https://doi.org/10.1038/274855a0

Fuzzi, S., Baltensperger, U., Carslaw, K., Decesari, S., Denier van der Gon, H., Facchini, M.C., Fowler, D., Koren, I., Langford, B., Lohmann, U., Nemitz, E., Pandis, S., Riipinen, I., Rudich, Y., Schaap, M., Slowik, J. G., Spracklen, D.V., Vignati, E., Wild, M., Williams, M., Gilardoni, S. (2015). Particulate matter, air quality and climate: Lesson learned and future needs. Atmos. Chem. Phys. 15, 8217-8299. https://doi.org/10.5194/acp-15-8217-2015

Grassberger, P., Procaccia, L. (1983). Characterization of strange attractors. Phys. Rev. Lett. 50, 346-349. https://doi.org/10.1103/PhysRevLett.50.346

Grewe, V. (2006). The origin of ozone. Atmos. Chem. Phys. 6, 1495-1511. https://doi.org/ 10.5194/acp-6-1495-2006

Hilborn, R. (2020). Chaos and Nonlinear Dynamics: An Introduction for Scientists and Engineers, 2nd Edition. Oxford University Press Inc., New York, USA.

Horna, J., Dionicio, J., Martínez, R., Zavaleta, A., Brenis, Y. (2016). Dinámica simbólica y algunas aplicaciones. Selecciones Matemáticas. 3, 101-106. https://doi.org/10.17268/sel.mat.2016.0 2.05

Iqbal, N., Fareed, Z., Shahzad, F., He, X., Shahzad, U., Lina, M. (2020). The nexus between COVID-19, temperature and exchange rate in Wuhan city: New findings from partial and multiple wavelet coherence. Sci. Total Environ. 729, 138916. https://doi.org/10.1016/j.scitotenv.2020.138916

Iwasaka, Y., Minoura, H., Nagaya, K. (1983). The transport and spacial scale of Asian dust-storm clouds: A case study of the dust-storm event of April 1979. Tellus B 35, 189-196. https://doi.org/10.3402/tellusb.v35i3.14594

Johns Hopkins Medical Institutions (JHMI) (2020). JHMI Clinical Guidance for Available Pharmacologic Therapies for COVID-19. https://www.hopkinsguides.com/hopkins/ub?cmd= repview\&type $=479-1129 \&$ name $=5$ 538747_PDF

Kampf, G., Todt, D., Pfaender, S., Steinmann, E. (2020). Persistence of coronaviruses on inanimate surfaces and their inactivation with biocidal agents. J. Hosp. Infect. 104, 246-251. https://doi.org/10.1016/j.jhin.2020.01.022

Lee, B., Kim, B., Lee, K. (2014). Air pollution exposure and cardiovascular disease. Toxicol. Res. 30, 71-75. https://doi.org/10.5487/TR.2014.30.2.071

Manríquez, R. (1987). Estructuras disipativas. De la termodinámica a la psicoterapia familiar. Rev. Asoc. Esp. Neuropsiq. 7, 435-454.

Ministry of Health of Chile (MINSAL). https://www.minsal.cl/ 
Ministry of the Environment of Chile (Ministerio del Medio Ambiente) (MMA). https://si nca.mma.gob.cl/index.php

Mouchet, J., Carnevale, O. (1997). Impact of changes in the environment on vector-transmitted diseases. Sante 7, 263-269.

Neiderud, C.J. (2015). How urbanization affects the epidemiology of emerging infectious diseases. Infect. Ecol. Epidemiol. 5, 27060. https://doi.org/10.3402/iee.v5.27060

Official Data COVID-19, Government of Chile. https://www.gob.cl/coronavirus/cifrasoficiales/

Pacheco, P., Mera, E., Salini, G. (2019). Medición localizada de contaminantes atmosféricos y variables meteorológicas: segunda Ley de la termodinámica. Inf. Tecnol. 30, 105-116. http://dx.doi.org/10.4067/S0718-07642019000300105

Rossi-Espagnet, A. (1983). Primary health care in the context of rapid urbanization. Community Dev. J. 18, 104-119. https://doi.org/10.1093/cdj/18.2.104

Ruelle, D.P. (2003). Extending the definition of entropy to non-equilibrium steady states. Proc. Natl. Acad. Sci. U.S.A. 100, 3054-3058. https://doi.org/10.1073/pnas.0630567100

Saliba, N.A., Massoud, R. (2011). A Comparative Review of PM Levels, Sources, and Their Likely Fates in the Eastern Mediterranean Region, in: Zereini, F., Wiseman, C.L.S. (Eds.), Urban Airborne Particulate Matter: Origin, Chemistry, Fate and Health Impacts, Springer, Berlin, Heidelberg, pp. 3-17. https://doi.org/10.1007/978-3-642-12278-1_1

Salini, G., Pérez, P. (2015). A study of the dynamic behavior of fine particulate matter in Santiago, Chile. Aerosol Air Qual. Res. 15, 154-165. https://doi.org/10.4209/aaqr.2013.10.0323

Salini, G.A. (2018). Understanding the chaotic behavior of particulate matter concentrations using nonlinear techniques. WIT Trans. Ecol. Environ. 30, 129-140. http://doi.org/10.2495/AIR 180121

Salini, G.A., Medina, E. (2017). Estudio sobre la dinámica temporal de material particulado PM10 emitido en Cochabamba, Bolivia. Rev. Int. Contam. Ambient 33, 437-448. http://doi.org/10.20 937/RICA.2017.33.03.07

Schwartz, J., Laden, F., Zanobetti A. (2002). The concentration-response relation between $\mathrm{PM}_{2.5}$ and daily deaths. Environ. Health Perspect. 110, 1025-1029. https://doi.org/10.1289/ehp.021 101025

Chile's National Air Quality Information System (SINCA). https://sinca.mma.gob.cl

Sprott, J.C. (1995). Chaos Data Analyzer software. http://sprott.physics.wisc.edu./cda.htm

Sprott, J.C. (2003). Chaos and time-series analysis, 1st Edition, Oxford University Press, Oxford, UK.

Walker, J.C.G. (1978). The early history of oxygen and ozone in the atmosphere. Pageoph 117, 498-512. https://doi.org/10.1007/BF00876630

Wang, W.C., Chen, K.S., Chen, S.J., Lin, C.C., Tsai, J. H., Lai, C.H., Wang, S.K. (2008). Characteristics and receptor modeling of atmospheric $\mathrm{PM}_{10}$ and $\mathrm{PM}_{2.5}$ at urban and rural sites in Pingtung, Taiwan. Aerosol Air Qual. Res. 8, 112-129. https://doi.org/10.4209/aaqr.2007.09.0039

Wilks, D., Farrington, M., Rubenstein, D. (2003). The Infectious diseases manual. Wiley Online Library. https://doi.org/10.1002/9780470757253.ch17

Wolf, A., Swift, J.B., Swinney, H.L., Vastano, J.A. (1985). Determining Lyapunov exponents from a time series. Physica D 16, 285-317. https://doi.org/10.1016/0167-2789(85)90011-9

World Health Organization (WHO) (2006). WHO Air quality guidelines for particulate matter, ozone, nitrogen dioxide and sulfur dioxide: global update 2005: summary of risk assessment. World Health Organization. https://apps.who.int/iris/handle/10665/69477

World Health Organization (WHO) (2013). Review of evidence on health aspects of air pollution - REVIHAAP Project. Technical report, World Health Organization, Regional Office for Europe, Copenhagen, Denmark. https://www.euro.who.int/_data/assets/pdf_file/0004/193108/REV IHAAP-Final-technical-report.pdf

Xu, H., Yan, C, Fu, Q., Xiao, K., Yu, Y., Han, D., Wang, W., Cheng, J. (2020). Possible environmental effects on the spread of COVID-19 in China. Sci. Total Environ. 731, 139211. https://doi.org/10. 1016/j.scitotenv.2020.139211 